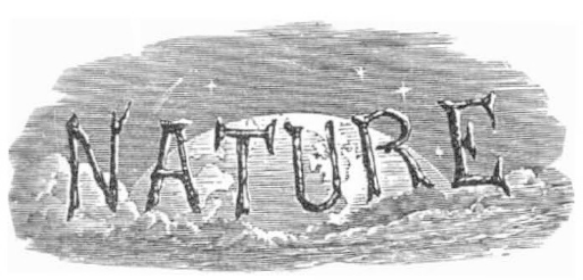

SATURDAY, MAY 2I, I927.

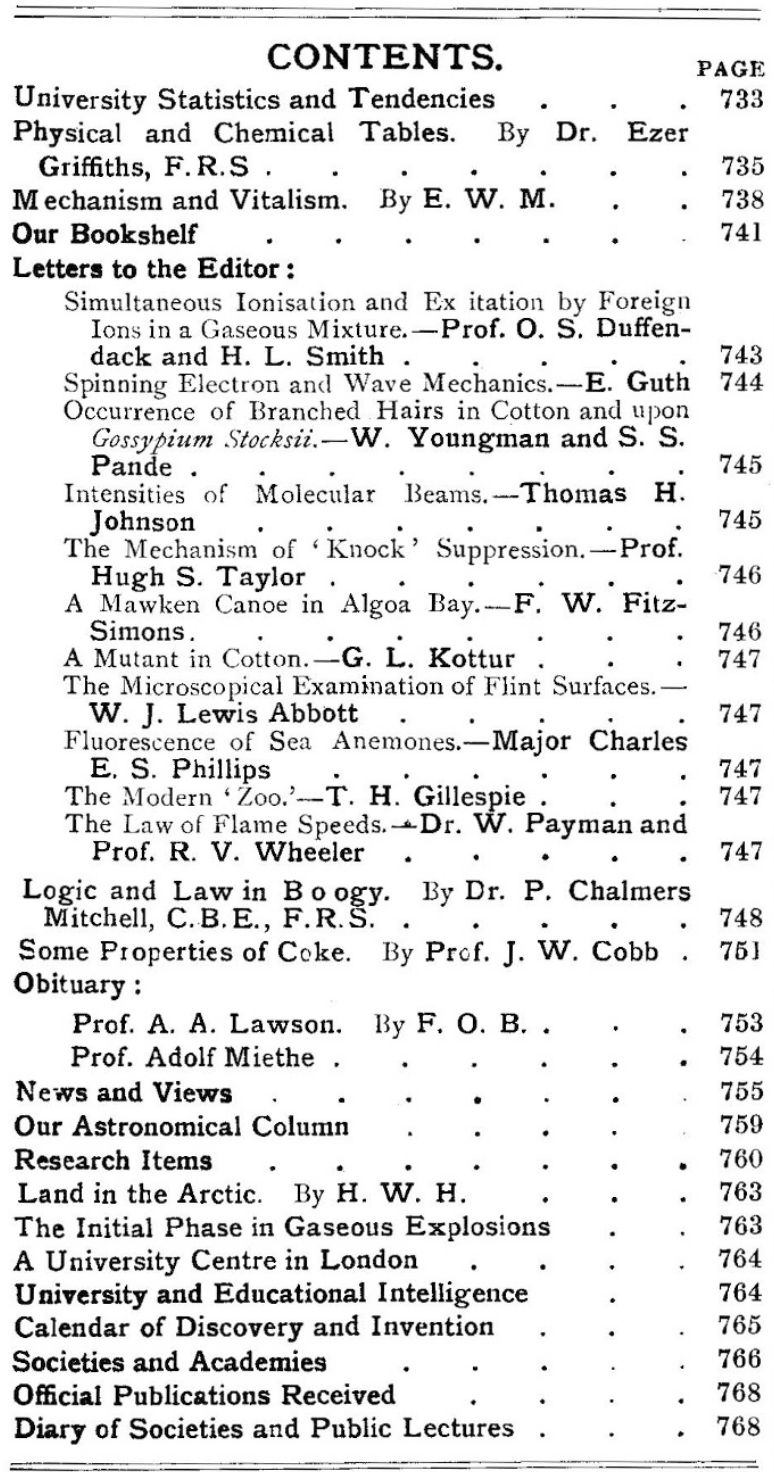

Editorial and Publishing Offices:

MACMILLAN \& CO., LTD.,

ST. MARTIN'S STREET, LONDON, W.C.2.

Editorial communications should be addressed to the Editor. Advertisements and business letters to the Publishers.

Telephone Number: GERRARD 8830.

Telegraphic Address: PHUSIS, WESTRAND, LONDON.

\section{University Statistics and Tendencies.}

QINCE the comparative tables of statistics before us ${ }^{1}$ have been compiled by the University Grants Committee, it is but natural that we should turn first to those which shed light upon the financial position. Nor need we make any apology ; for unless that position be sound there can be little expectation that the function of the universities can satisfactorily be discharged. Happily the accounts show a decided and general improvement, particularly when it is noted that only in the case of thirteen institutions has expenditure exceeded income; and even in these cases the deficits were small and were due to the fact that the institutions concerned met out of income an unusual amount of capital or other non-recurrent expenditure.

The improved position is due largely to increased Treasury grants made upon the recommendation of the Grants Committee, and indicates very clearly that that recommendation has been justified. At first glance the increase in "Government Grant," 35.9 to 39.5 per cent., does not appear to be great, but it has nevertheless been an excellent incentive. Not only have the institutions suffering from a deficit been reduced from twenty-four to thirteen, but also, as the Committee points out, there is another gratifying fact which does not appear in the tables: during 1925-26 reductions of debt to the amount of more than $£ 50,000$ were effected. This possesses a special significance when it is observed that increases of salaries of teaching staff cost more than $£ 88,000$; increases in departmental and laboratory maintenance more than $£ 23,000$; in general libraries and museums, $£ 24,000$; in repairs and maintenance of buildings, $£ 38,000$; in capital expenditure met from income, $£ 57,000$; and in grants to students' societies, $£ 10,000$. The increase of government grants was not, of course, wholly responsible. Income from local education authorities, from endowments, donations, subscriptions, and students' fees, was, in each case, greater than in the preceding year.

With regard to the number of full-time students it may be said that the year has shown a return to what may be normally expected. Actually there is a slight decrease from 41,794 in $1924-25$ to 41,443 in $1925-26$, but this is largely accounted for by the fall in the number of ex-service students from 263 to 17. Any small aggregate decrease in the number of full-time students is not, as the

1 University Grants Committee. Returns from Universities and University Colleges in receipt of Treasury Grant, 1925-1926. Pp. 24 (London: H.M. Stationery Office, 1927.) $3 s$, net.

No. 3003, VoL. 119] 
Committee points out, very surprising in view of the prolonged industrial depression; and against that small decrease must be set an encouraging increase in the number entering for the first time upon degree or diploma courses.

Whatever may be the numbers of students, the main interest must be concentrated upon what they are doing; and here there emerge facts which at present we shall not attempt to explain, since they depend upon conditions which are more or less familiar to us all. In the medical, technological, and agricultural groups there is a fall, the decreases being 1000, 152, and 70 respectively. In the pure science group there is a slight increase, while in the arts group there is the substantial increase of 869. As to what specific subjects are proving more or less popular, however, the Committee finds it difficult, for obvious reasons, to carry its analysis far enough. It realises, nevertheless, that it is possible for certain subjects to become rather more popular than is desirable in the national interest. Is philosophy, for example, "not tending to be unduly neglected by our arts students"? Or is chemistry " not tending to attract an unduly large proportion of our science students"?

For our part we do not lack evidence to show that chemistry is, at present, attracting a number of students which may be unduly large. But on the question as to whether this is a matter for alarm or congratulation we do not propose to speak at the moment. We do, however, regret the tendency -and we cannot fail to note that in this age of specialisation it must inevitably increase-for students to neglect philosophy. Nor would we confine that regret solely to the fact that it is neglected by arts students. Philosophy is not the monopoly of any particular group : it is an essential to every student. Let there be no mistake. We are not thinking of it as a form of metaphysics down the tangled by-paths of which we would have science students lose themselves. But if science means, ultimately, an enlargement of experience, we regard philosophy as a critique of that experience.

If we appear to over-emphasise this point in connexion with the courses-in arts or scienceof university students, let our excuse be that we claim a lofty view of the function of a university -a view which made us sympathetic, some three or four years ago, with the writer of an article in a prominent university magazine. "Let us learn from others and make our own peculiar gift to the common stock of undergraduate life. If, however, we are not prepared to do this, then let us at least be honest and call ourselves first-rate teeth-extractors, assiduous engine-wipers, and the like, but not 'varsity men."

This matter of the actual subjects followed by university students leads us directly to another important aspect which the present Committee's returns place before us. The whole document seems to us to fall into three main parts: that dealing with accounts, the congratulatory nature of which we have already indicated; that dealing with the subjects and groups of subjects which are being followed in the universities; and that dealing with a matter upon which there is, as yet, little reason to regard as satisfactory. We refer to university libraries. In this connexion a new table of figures has been introduced into the Returns before us. In its general reports in 1921 and 1925, the Committee reminds us, not only was great stress laid upon the importance of well-equipped libraries, but their maintenance and development was insisted upon as one of a university's primary duties, "since defects in this central organ must inevitably have a harmful effect upon the work both of teachers and of students in all departments alike." But the state of affairs revealed by the Library Table, in spite of the fact that a larger sum was spent in 1925-26 than in the preceding year, still presents " an essentially gloomy picture."

In the universities of Great Britain (excluding Oxford and Cambridge) the total expenditure on libraries was $£ 120,616$. This sum was made up of $£ 46,280$ (salaries), $£ 58,237$ (books), $£ 8946$ (binding),

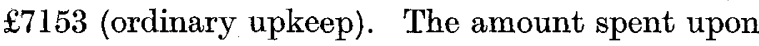
books by more than fifty institutions of university rank is astonishingly small, and while the Committee is not unaware of the difficulties which beset comparisons between our university conditions and those of other countries, it does not hesitate to justify its phrase "an essentially gloomy picture" by comparison with the United States. We cannot improve the wording of the Committee: ". . . we could not escape some rather melancholy reflections at finding that for the item of expenditure on books during the academic year 1925-26 the total figure for all our grant-aided universities and colleges put together appeared to be little larger than the combined figure for the universities of Harvard and Yale. . . ."

We said above that our reflections concerning the neglect of philosophy led us directly to the important aspect which the returns show us of university library conditions. We do not imagine that, for those who share our views as to the function of a university, any further explanation is needed.

No. 3003, Vou. 119] 